\title{
Uma experiência de atividade-intervenção: a sensibilidade como ferramenta de luta
}

\author{
An activity-intervention experience: sensitivity as a tool for struggle
}

Catarina Resende; Júlia Virginio Câmara; Júlia Bodden Craveiro; Jully Wanny da Silva Rocha; Luiza S. Loyola de Araújo; Marcelle da Silva Freitas; Mariana Thomaz de Aquino Ribeiro; Vic Guimarães

Universidade Federal Fluminense

\section{RESUMO:}

Este trabalho faz uma análise de uma atividade-intervenção proposta pelo grupo de pesquisa CorpoSSutis, suscitada ao encontrar um cenário de retaliação governamental ao ensino nas universidades públicas. Diante desse contexto, e a partir do engajamento da UFF com outras universidades, nossa proposta surgiu em conjunto com uma série de atividades abertas à comunidade. Um grupo de pesquisa que estuda a formação de um corpo-clínico sensível foi sensibilizado pelo fato de boa parte das pesquisas acadêmicas permanecerem enrijecidas quanto ao diálogo com o fora, entre a população e a produção científica e tecnológica universitária. Ao instaurar a pergunta disparadora "Como Sensibilizar os Corpos para Luta?", a atividadeintervenção em foco pode despertar conversas sobre possíveis relações entre sensibilidade, luta e coletividade.

Palavras-chave: coletividade; luta; sensibilidade; corporeidade

\section{ABSTRACT:}

This article analyzes an activity-intervention, proposed by the research group CorpoSSutis, raised by finding a scenario of government retaliation against education in public universities. Given this social context and from Universidade Federal Fluminense engagement with other universities, our proposal emerged as part of a series of activities open to the community. A research group that studies the sensitive body in psychological clinic questioned the current problem of academic research remaining closed to dialogue with the outside, between the population and the scientific and technological production. By introducing the triggering question "How to Sensitize Bodies to Fight?", the activity-intervention in focus could awaken conversations about possible relations between sensitivity, struggle and collectivity.

Key-words: collectivity; struggle; sensitivity; corporeality

DOI: 10.12957/mnemosine.2020.57650

\section{Movimento de ensino - de dentro para fora}

Há alguns anos a educação pública brasileira vem sofrendo uma série de ataques pelo governo federal, dentre os quais o corte de verbas vem se tornando cada vez mais rigoroso. Em 
48 Catarina Resende; Júlia Virginio Câmara; Júlia Bodden Craveiro; Jully Wanny da Silva Rocha; Luiza S. Loyola de Araújo; Marcelle da Silva Freitas; Mariana Thomaz de Aquino Ribeiro; Vic Guimarães.

abril de 2019, três universidades federais foram acusadas nominalmente pelo então ministro da Educação de serem locais de "balbúrdia", sendo ameaçadas de sofrer sanções no repasse de verbas. Dentre aquelas, se incluía a Universidade Federal Fluminense (UFF), a casa do nosso grupo de pesquisa CorpoSSutiS. Tal declaração gerou polêmica e reações em cadeia na comunidade interna, bem como com a sociedade em geral, entidades civis, jornalistas, artistas e personalidades que defendem um ensino público e inclusivo de qualidade em nível nacional. Em nós, como integrantes de grupo de pesquisa de iniciação científica (PIBIC), pudemos sentir um incômodo imenso pelo absurdo de desqualificar desse modo uma instituição de ensino, pesquisa e extensão.

Diante disso, enquanto comunidade acadêmica, entendemos que não podíamos só nos revoltar entre nós, mas sim fazer algo a respeito, dentro e fora da UFF. E, para isso, tivemos que nos reaver com uma problemática que é a distância, na maior parte das vezes gigantesca, entre a população e a produção científica e tecnológica universitária. $\mathrm{O}$ ataque político e midiático ao ensino público e inclusivo das universidades se aproveitou dessa distância para descredibilizar os projetos de pesquisa, inovação e inserção no mercado que são feitos de forma muito compromissada nesses espaços. Reforçando tudo isso, a UFF, no mês de maio de 2019, se engajou junto a outras universidades e entidades em uma série de atividades abertas à comunidade. Tinha início o evento "UFF nas Praças", cujo objetivo era o de levar o maior número de projetos e ações universitárias até locais de grande circulação da população e mostrar, para quem se interessasse, o que temos feito para contribuir diretamente com a sociedade, dando retorno aos contribuintes que também sustentam esse ensino com seus impostos.

Mas os tempos de ataque são também tempos de defesa; e ainda mais que isso, podem ser tempos de invenção: criamos nossa primeira "oficina"² para participar do "UFF nas Praças" no dia de um amplo protesto contra os ainda mais severos cortes na educação. Foi uma mobilização de todos os estados e DF no Brasil. Com uma pesquisa que visa investigar, manusear e explorar a formação de um Corpo-Clínico Sensível ${ }^{3}$, nos questionamos: como manejar essa sensibilidade em tempos tão críticos e difíceis?

Em meio ao caos, nos colocamos firmes, apostando no nosso trabalho, mesmo sentindo muitas dores por consequência dos ataques. Ficamos pensando no esforço, na potência e na garra de todos os docentes, discentes, extensionistas, pesquisadores, técnicos e funcionários terceirizados que estavam ali defendendo não só os seus trabalhos "individuais", mas, 
sobretudo, a Universidade Pública como projeto político e pedagógico de produção de conhecimento, de políticas públicas e de ofertas de serviços à comunidade. Estávamos ali reunidos na Praça Araribóia, no terminal rodoviário do centro de Niterói, no esforço de expressar a vida que pulsa do meio acadêmico: departamentos de ensino se juntaram para oferecer café da manhã aos transeuntes, aproveitando para conversar - entre um pedaço de bolo e um gole de café - sobre a importância social direta da universidade na vida das pessoas, com grupos de pesquisa e extensão de todas as áreas de conhecimento presentes, compartilhando experimentos, atividades e oferecendo serviços.

Um dos impactos mais imediatos em nossos corpos, ao viver essa experiência na praça, foi perceber a imensa desarticulação entre as áreas ou cursos da universidade. Nós mesmos, os docentes, discentes, extensionistas, pesquisadores, técnicos e funcionários terceirizados, não temos contato e conhecimento com o que está sendo produzido "intramuros". Mas também foi um respiro perceber a profusão de pesquisas dialogando em espaço público, espaço investido pelo coletivo, nos fazendo reparar que esses diálogos, que raramente se instauram no nosso convívio, são possíveis. Esse ponto trouxe novas inflexões dentro do grupo de pesquisa: Como nos perguntar, durante o percurso de trabalho, qual a nossa intenção ao pesquisar? Para quem e a serviço de quê, nós, acadêmicos-pesquisadores, temos construído a pesquisa? Precisamos garantir que esse trabalho, além de alimentar a instituição que o sustenta, ganhe pernas longas, chegando mais diretamente à sociedade. Esse é o sentido que queremos dar a ver ao pesquisar.

O nosso grupo, nesse contexto, se propôs a experimentar uma "oficina”, uma espécie de atividade-intervenção na praça que pudesse despertar uma conversa sobre possíveis relações entre sensibilidade e coletividade nos momentos em que também estávamos lutando por nossos direitos. Era um dia nublado, chuvoso, que nos convocava a criar uma outra disposição corporal para nossas práticas semanais da pesquisa. Em meio a tantas movimentações acontecendo ao mesmo tempo para organizar o evento, pegamos as cadeiras que estavam reservadas para nossa "oficina", "abrimos" um cantinho debaixo da enorme tenda azul. Organizando nossa roda abrigada da chuva, escrevemos um cartaz-convite com os dizeres: "Como sensibilizar o corpo para a luta?". 
50 Catarina Resende; Júlia Virginio Câmara; Júlia Bodden Craveiro; Jully Wanny da Silva Rocha; Luiza S. Loyola de Araújo; Marcelle da Silva Freitas; Mariana Thomaz de Aquino Ribeiro; Vic Guimarães.

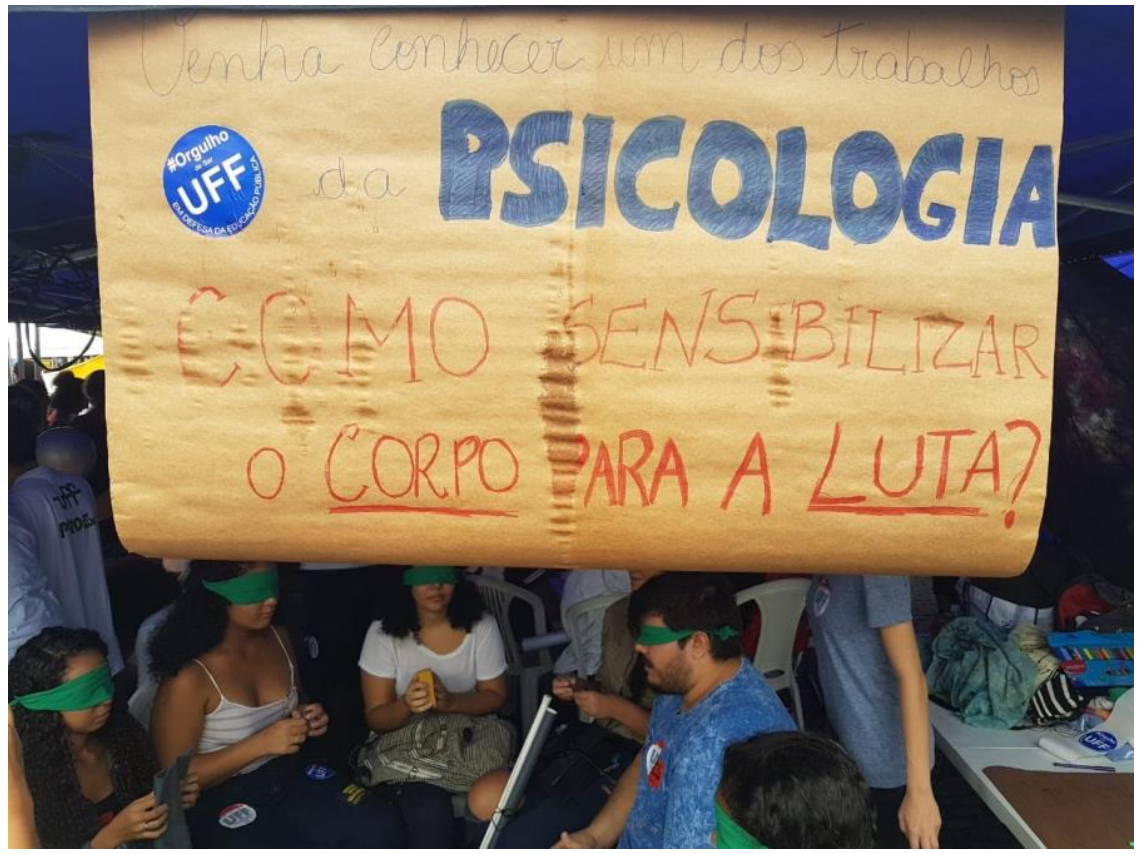

Cartaz - Evento UFF nas Praças 


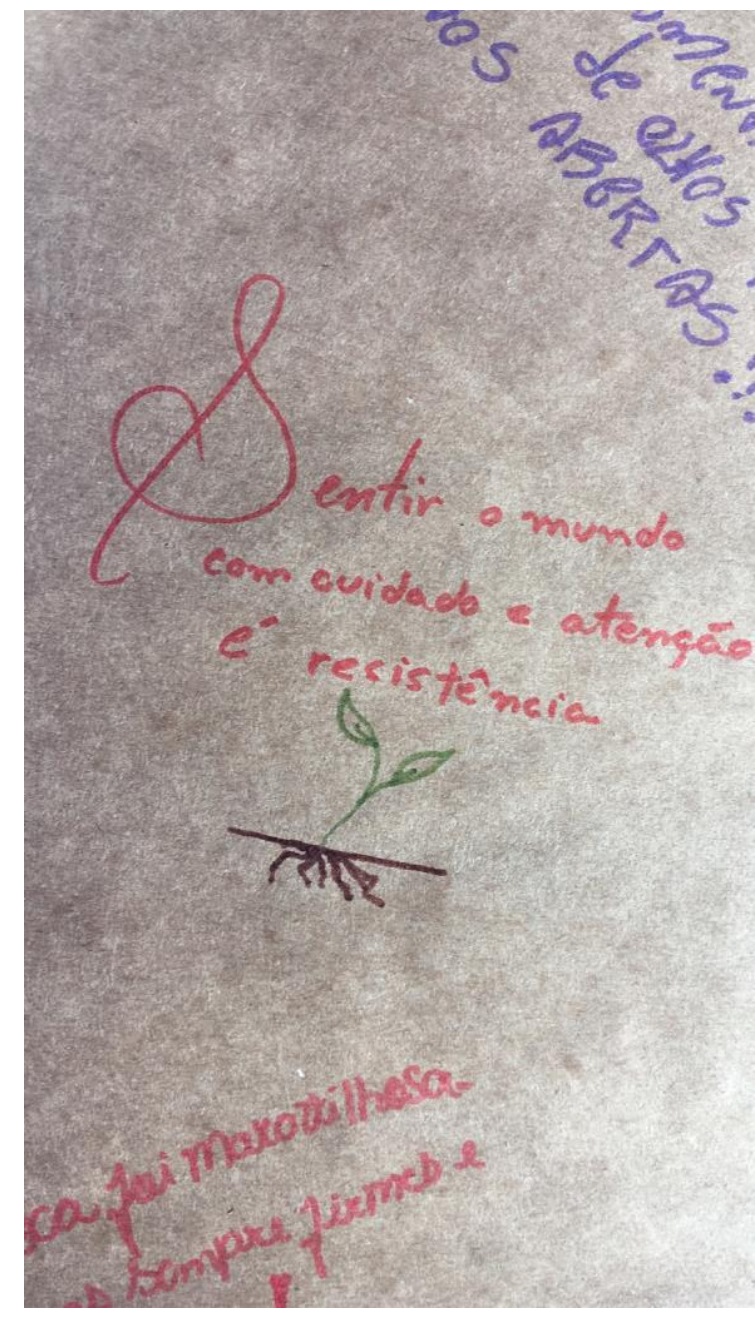

Registro sensível - Evento UFF nas Praças

\section{Como Sensibilizar os Corpos Para a Luta?}

A princípio, parecia uma contradição. Sensibilidade e Luta ${ }^{4}$ ? Sim. E essas palavras foram encontrando nos corpos dos participantes suas composições paradoxais, suas “corposições" (RESENDE et al., 2017) e, também, suas diferenças no decorrer da oficina. Na conversa posterior à dinâmica de sensibilização, acrescentávamos outras provocações à questão inicial: "como isso que experimentamos na dinâmica nos ajuda a viver juntos?”, trazendo uma das perguntas disparadoras da nossa pesquisa (RESENDE, 2018); “pode a sensibilidade ser uma ferramenta de luta?", completávamos, inspiradas por Franco Berardi (2011).

No início, as pessoas que transitavam rotineiramente pela praça apenas continuavam passando, sem parar para ver o que estava acontecendo naquele espaço. Nós tivemos que fazer uma força para chamá-las e pedir para que elas pudessem reparar na potência do evento daquela tarde. Parecia haver uma resistência enorme de "sair da zona de conforto" ou quebrar com o automatismo e a pressa do cotidiano, de sentar numa roda apertadinha de cadeiras com 

Ribeiro; Vic Guimarães.

desconhecidos vendados e, de fato, “colocar o corpo para jogo". E, assim, propusemos a oficina: com uma venda nos olhos, os participantes eram convidados a "sentir" o objeto que lhes era oferecido, explorá-lo com outros sentidos (que não a visão) e, depois, passar para a pessoa ao lado. Propusemos que cada pessoa tivesse apenas um objeto nas mãos por vez. Eram objetos ordinários, que pudessem estimular plurisensorialidades, variando em textura, peso, plasticidade, densidade, tamanhos, odores, sonoridades: bolinhas lisas, rugosas, com sininho, chocalhos, carrinho de plástico, esponja, folha seca, saco plástico com água dentro, galho seco, bolinha de sabão, mola de plástico, feltro etc. Assim, ao mesmo tempo em que os participantes exploravam sensorialmente aquilo que chegava às suas mãos, precisavam encontrar um ritmo próprio, e enquanto grupo, para a passagem dos objetos de um para outro. Eram exercitadas as capacidades de sintonizar com o outro e em grupo, afinando as mais sutis modulações das comunicações entre corporeidades. Qual o tempo “justo" para explorar o objeto e qual o tempo "justo" de passar adiante? Como comunicar com o outro sem poder vê-lo e sem falar? Repetíamos muito para eles: "Como sensibilizar o corpo para luta?" "Como essa experiência nos ajuda a viver juntos?".

Perguntas simples, mas que provocaram reflexões interessantes dos participantes. Uma pessoa, por exemplo, levantou a questão do cuidado: Como respeitar o ritmo do grupo sem interferir no tempo da outra em explorar e descobrir aquele objeto? Discutimos ali como isso é relevante para momentos de luta política, em que grupos repletos de diversidade de todos os tipos se unem por uma causa, a fim de ganhar força e visibilidade. As pessoas puderam refletir como a sua "pressa" ou sua "demora” influenciam de formas diferentes no ritmo do grupo.

\section{(Com)partilha de afetos - pistas sobre o cuidado}

Assim como as perguntas, respostas recebidas nos trouxeram a força e a beleza da sensibilidade compartilhada, nos dando pistas sobre a importância do nosso trabalho para as relações que temos, enquanto sociedade, reproduzido. O discurso operante hoje, de um sujeito que se preocupa com o individual, nos provoca um tipo de cuidado: de si para si - um falso cuidado. Diferente desse automatismo a que, num piscar dos olhos, estamos entregues, a dinâmica nos mostrava que o inverso é onde se encontra a nossa potência. Isso quer dizer que, no contágio entre o coletivo, como o encontro de um ritmo sem utilizar o recurso da fala e da visão, sintonizamos com o que temos de mais potente: nossas marcas, memórias e histórias transformadas em pulsações-narrativas que podem ser construídas a partir da relação sutil com 
o outro. Quando apostamos numa luta através da potência da composição dinâmica de forças, e não da destruição da diferença, são esses os recursos e ferramentas utilizados para nos mantermos juntos, com um sentido de construção coletiva atravessando as fronteiras entre a luta e o cuidado.

Pensando nas diferenças que emergiram no dia do "UFF Na Praça", acreditamos que nós, integrantes do grupo CorpoSSutis, chegamos a uma reflexão tardiamente formulada por uma das integrantes: "na construção de um cuidado compartilhado, preciso encontrar espaço para expressar as minhas marcas. Só consigo viver junto no momento em que o 'junto' inclui diferenças de densidade, peso, contorno, temperatura, som, cheiro... Só consigo expandir e sustentar minhas lutas com firmeza se estiver de pé sobre meus territórios existenciais". Não nos recordamos se na época a gente tinha pensado algo parecido com isso ou se a gente tinha recebido alguma resposta que havia se apresentado dessa forma, mas é dessa maneira que o grupo atualiza esse enunciado.

Compartilhamos, na sequência, um relato intensivo carregado de afetos gerados pelas reflexões oriundas da experiência com a atividade-intervenção. Escrito por uma das participantes da pesquisa, após a proposição da atividade, expressa sem "explicar" como entendemos corpo sensível:

"Me sinto mais presente tanto comigo, tanto na pesquisa. O que eu quero dizer é que o que estamos trabalhando agora, e tudo isso que nos marca, ao mesmo tempo que mostra nossas dificuldades e nossos caminhos dolorosos, também nos mostra que sem as cicatrizes a gente não pode mostrar o quanto nós fomos fortes para superar a dor por trás delas.

E a gente doeu, hein... a gente doeu, fez machucado, mas saramos e estamos mais endurecidas, mais maduras. Acredito que agora realmente conseguimos pegar uma na mão da outra com firmeza. Acho que é essa a palavra que estava me faltando: Firmeza.

Sinto o meu corpo firme com vocês e aqui vai uma pequena poesia que está se fazendo no presente em que penso

Meu corpo firme

com os pés no chão

estabelece uma posição. 

Ribeiro; Vic Guimarães.

Um posicionamento.

Sinto-me cheia de ar e ao mesmo tempo

com a musculatura contraída

porque forte e porosa.

Ninguém me tira da minha posição

do meu posicionamento

mesmo sabendo que piso em areias molhadas pela correnteza do mar

Ninguém me tira mas eu posso me mover

minha posição é mais que isso

é um posicionamento

e eu me faço

para escutar

Escuto de orelhas em pé

e olhos atentos

continuo no meu posicionamento mas me afasto pra lá

Pra cá vejo outros posicionamentos

que se estabelecem ao meu lado

e trazem o quentinho do sol

Continuo na minha posição

mas agora de mãos dadas aqueles

que permanecem olhando o horizonte comigo

Sinto que a poesia ainda não terminou mas sigo, como sigo junta a vocês.” (Júlia Câmara).

Um Novo Cenário para/de Atividade-Intervenção 
Em meados de outubro de 2019, fomos convidadxs a compor com o evento "Políticas/poéticas do contágio: ensaios de viver entre muitxs", realizado na Universidade do Estado do Rio de Janeiro (UERJ). Para dividir o espaço com tantas pessoas e tantas atividades interessantes, resolvemos, então, propor a atividade-intervenção que havíamos feito no "UFF nas praças", já que entendíamos que seria uma proposta sensível e potente para as provocações do encontro. Chegamos no enorme campus vertical de concreto da UERJ e nos instalamos no hall do $10^{\circ}$ andar, onde muitas pessoas passavam entre uma sala e outra do Instituto de Psicologia, buscando as atividades acadêmicas, oficinas e palestras que aconteciam em função do evento. Colocamos carteiras escolares e a mesma provocação no cartaz-convite que utilizamos na praça de Niterói, mas agora a pergunta trazia "os corpos" no plural, como mais um gesto de atualização do nosso grupo impulsionado pelas reflexões geradas na atividade anterior. Ali se instalava uma espécie de segunda praça: ainda que dentro de um edifício, era um espaço de trânsito, aberto à comunidade, aos desavisados e curiosos que por ali passassem.

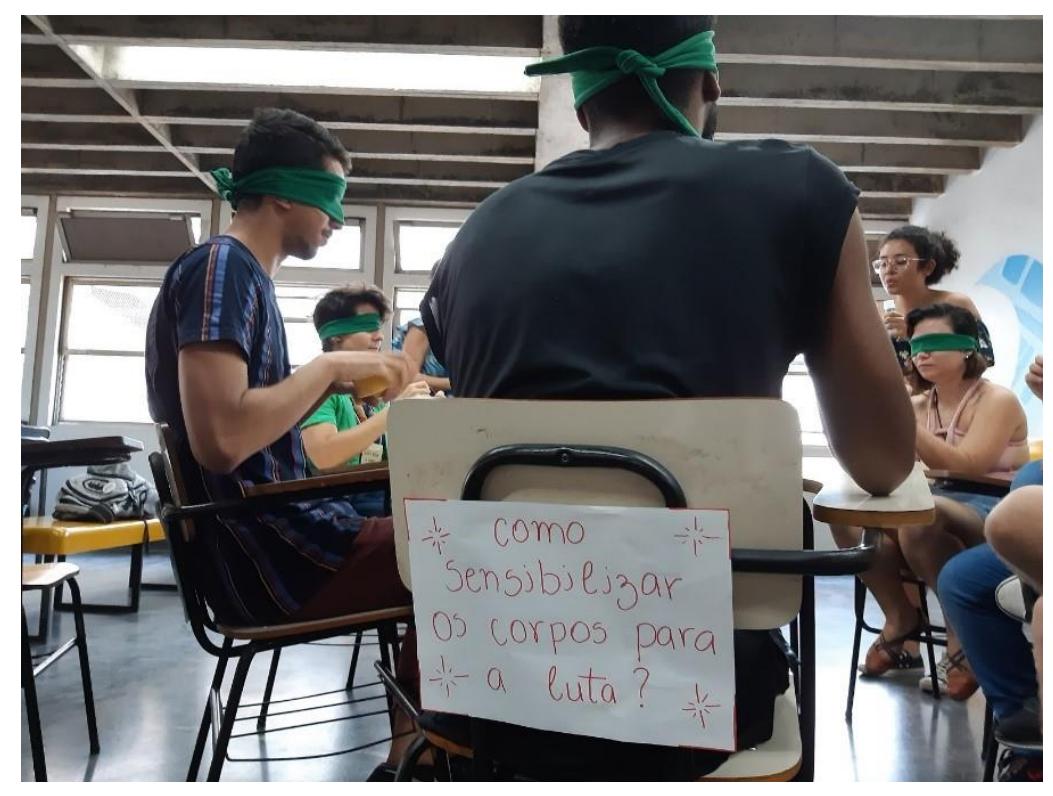

Oficina em curso com cartaz - Evento Políticas e Poéticas do Contágio

Da mesma forma que aconteceu em Niterói, na "praça da UERJ" as pessoas pareciam tímidas e não queriam participar da atividade, a princípio. Tivemos que chamá-las, ir instigando-as, para que elas pudessem, pouco a pouco, sentar nas carteiras e ir se sentindo confortáveis com as vendas nos olhos. Naquele momento, tentávamos sustentar uma posição de proponentes e participantes da nossa atividade (assemelhando a nossa posição de sermos 

Ribeiro; Vic Guimarães.

mutuamente sujeitos e objetos de nossa pesquisa), buscando a curiosidade das pessoas transeuntes, nos encorajando a dirigirmo-nos a elas e participar junto. Mesmo com a diferença de circulação de gente entre as praças das duas cidades, outra semelhança ocorreu: as primeiras rodas da "oficina" eram tímidas, mais vazias... Depois, parecia que uma atmosfera de contágio era criada e o "entorno" se intrigava com as pessoas em roda, vendadas, muito conectadas e concentradas, repassando os mais diversos objetos. A curiosidade por aquele campo gravitacional instaurado também parecia convidar, gradativamente... E, ao final, nos atrasamos para o horário do almoço pela quantidade de participantes e questões que surgiram ao final da atividade!

Uma das participantes nos contagiou com seu envolvimento sensível na prática e entrega, quando pode fazer muitas analogias da atividade com a sua vida cotidiana. Wanessa estava no evento com sua banca ao lado da nossa roda, expondo livros de poesias da Esquina Editorial, produzidos pelo movimento literário e da poesia falada da Cidade de Deus. Sua presença era um corpo vivo que pulsava e trocava afetivamente com nosso grupo ${ }^{5}$, que também tinha levado para vender algumas zines de poesia produzidas artesanalmente por algumas de nossas integrantes-poetas. Para que ela pudesse participar da nossa atividade, nos articulamos como na "dança das cadeiras": trocávamos de lugar com ela, na sua banca de livros. A partir da experiência do "dar e receber" objetos com os olhos vendados, Wanessa abria mais o nosso olhar para a multiplicidade das lutas cotidianas e a pluralidade de corpos a serem sensibilizados. A luta, segundo ela, mulher trans, negra e periférica, começa ao escolher uma roupa para sair de casa rumo a uma entrevista de emprego, por nunca poder prever como o empregador vai "receber" a sua imagem corporal no encontro - fazendo uma analogia ao desafio de se abrir para “dar e receber" objetos imprevistos na oficina. De alguma forma, o "não saber o que está por vir" por estar vendada a aproximou da experiência de nunca saber de que "armas vai precisar" na lida/luta com o outro pelo simples fato de existir no seu corpo. Sobre a experiência vendada, Wanessa trouxe ainda outro nexo com sua vida doméstica: sua mãe perdera a visão com o agravamento da diabetes, e agora, sendo sua cuidadora, refletia sobre a coragem que é preciso ter apenas para se mover e se deslocar pela casa nestas novas condições adversas. Então, começamos a pensar juntxs como seria essa experiência entre coragem e confiança num corpo que perde a visão já em idade avançada. Ainda que, inicialmente, a "Luta" à qual nos referíamos na primeira "oficina” trouxesse expressivamente uma dimensão macropolítica, a cada rodada e 
troca de experiências redimensionávamos outras formas de luta, que tinham como campo de batalha o próprio corpo: micropolíticas ${ }^{6}$ cotidianas, afetivas, existenciais.

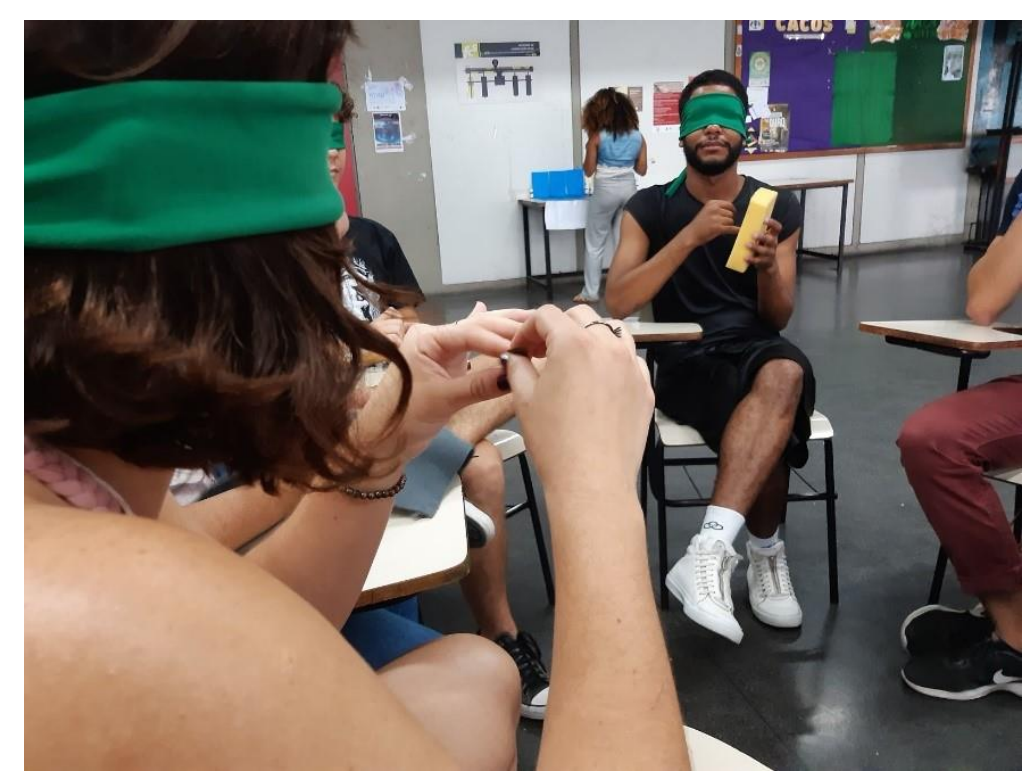

Oficina em curso sentindo os objetos - Evento Políticas e Poéticas do Contágio

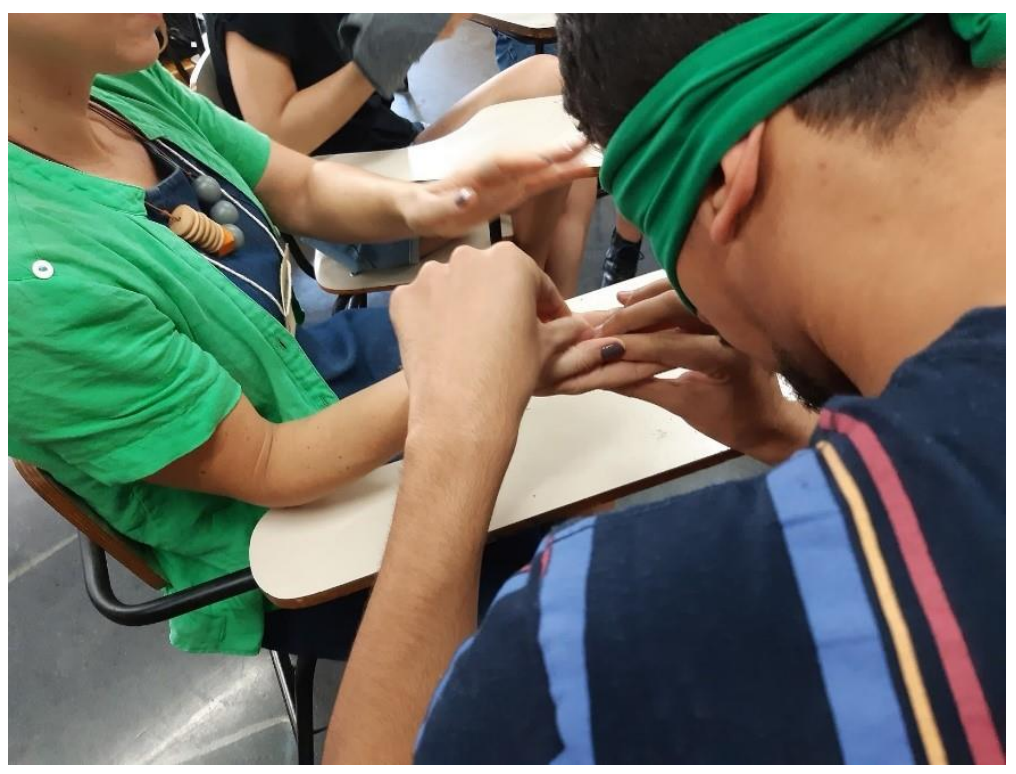

Oficina em curso sentindo e passando os objetos - Evento Políticas e Poéticas do Contágio

\section{O que da experiência nos toma de fora para dentro?}

Entendemos que no processo de pesquisar precisamos estar abertos ao que nossos corpos nos interpelam a experienciar no encontro com o outro: a conexão com as diferenças. Além disso, nossas trocas "extramuros" da universidade têm sido oportunidades enriquecedoras para desestabilizar certas convicções enquanto "sujeitos" da pesquisa, renovando nossas 
58 Catarina Resende; Júlia Virginio Câmara; Júlia Bodden Craveiro; Jully Wanny da Silva Rocha; Luiza S. Loyola de Araújo; Marcelle da Silva Freitas; Mariana Thomaz de Aquino Ribeiro; Vic Guimarães.

questões a partir do que a "rua" nos ensina. As relações sensíveis entre propositorxsparticipantes criam um campo de transição difícil de ser definido - ao final de cada encontro há a possibilidade de uma renovação da pesquisa. Quando Wanessa traz questões sobre como sensibilizar o seu corpo para a luta, identificando uma luta diária tão contundente quanto invisível, nos oferece sua pesquisa particular num trânsito de forças sensíveis que faz transbordar as relações sujeito-objeto, universidade-rua, propositora-participante como instâncias fixas. Os papéis transitam ao permitirmos que histórias outras perpassem sensivelmente nossos corpos, sintonizando em uma pulsação coletiva. Assim, o exercício de "levar a universidade pras ruas" como forma de luta política e aproximação com a sociedade resultou em trazer, reciprocamente, as ruas para a universidade: incorporando novas provocações às nossas questões, ampliando nossas sensibilidades e assumindo o desafio ético de estarmos, como pesquisadorxs, à altura do que registrou uma das participantes após nossa atividade-intervenção: "Ouvir o mundo com cuidado e atenção é resistência”.

\section{Referências}

BERARDI, Franco. Entrevista com Franco Berardi (Bifo), publicada em 29/01/2011, no periódico espanhol Público. Tradução do blog Boca do Mangue. Disponível em: https://bocadomangue.wordpress.com/2011/01/30/\%e2\%80\%9ca-sensibilidade-e-hojeo-campo-de-batalha-politico\%e2\%80\%9d/. Acesso em 29 de julho de 2020.

RANCIÈRE, Jacques. A partilha do sensível: estética e política. São Paulo: EXO experimental org.; Ed. 34, 2009(a). 2a Ed.

RESENDE, Catarina. Uma arte das conexões sutis: a formação de um corpo-clínico sensível. Projeto de pesquisa. Instituto de Psicologia. Universidade Federal Fluminense. Niterói: 2018.

RESENDE, Catarina et al. Corposições entre o ver, o dizer e o agir. Fractal, Rev. Psicol., v. 29 - n. 2, p. 135-142, 2017. Dossiê Corporeidade.

ROLNIK, Suely. A hora da micropolítica. São Paulo: N-1 Edições, 2015. Série Pandemia.

Catarina Resende Júlia Virginio Câmara Júlia Bodden Craveiro Jully Wanny da Silva Rocha Luiza S. Loyola de Araújo Marcelle da Silva Freitas 


\section{Mariana Thomaz de Aquino Ribeiro \\ Vic Guimarães}

Universidade Federal Fluminense - Niterói.

E-mail: luizasloyola@gmail.com

\footnotetext{
${ }^{1}$ Link para mais informações: http://www.uff.br/?q=noticias/07-05-2019/uff-nas-pracas-acao-de-divulgacao-dosprojetos-da-uff

${ }^{2} \mathrm{O}$ termo entre aspas sinaliza um estranhamento. De saída, podemos dizer que nomear tal dispositivo de "oficina" correspondeu a uma adequação formal aos modelos de atividade previamente estabelecidas pelo evento. Contudo, com o tempo fomos entendendo, principalmente, no ato de elaborar este texto, que estávamos criando uma "atividade-intervenção" mútua entre os participantes envolvidos, incluindo-se aí as pessoas que chegavam, os objetos, os territórios e o próprio grupo de pesquisa.

${ }^{3}$ Projeto de Iniciação Científica PIBIC - Uma Arte das Conexões Sutis: A Formação de um Corpo-Clínico Sensível. 2018 - Hoje. Instituto de Psicologia/ Departamento de Psicologia/ Laboratório de Subjetividade e Corporeidade (CORPOREILABS).

${ }^{4}$ Sobre a relação entre o sensível e a política, ver Rancière (2009).

${ }^{5}$ Troca esta que se estendeu afetivamente durante a feitura dessa escrita, quando retomamos o contato com Wanessa compartilhando e recebendo o consentimento da sua presença nas reflexões que por ora expomos.

${ }^{6}$ Sobre a relação entre micropolítica e saber-do-corpo, ver Rolnik (2015).
} 